\title{
К ВОПРОСУ О ПРОПОРЦИОНАЛЬНОМ РЕГУЛИРОВАНИИ БАНКОВСКОЙ ДЕЯТЕЛЬНОСТИ В РОССИИ
}

\section{TO THE ISSUE OF PROPORTIONAL BANKING REGULATION SYSTEM IN RUSSIA}

M. Kyrlan

Summary. The article analyses the issue of the legal and economic nature of credit organizations based on a basic and universal license. Also, the essence of proportional regulation of the Russian banking system is investigated, in connection with which the following tasks are distinguished: to consider the formation of the Russian banking system at the present stage; explore the transition to proportional regulation of the banking system; to determine the prospects for the development of the banking system of Russia in connection with the transition to proportional regulation.

Keywords: Central Bank, banks with general license, banks with basic license, the banking system.

\author{
Кырлан Марчел \\ Cтариий преподаватель, Финансовый университет \\ при Правительстве Российской Федерации (г. Москва) \\ marcel_carlan2003@yahoo.com
}

Аннотация. В статье рассматривается вопрос правового и экономического регулирования кредитных организации на основе базовый и универсальной лицензии. Также рассматривается сущности пропорционального регулирования российской банковской системы, в связи с чем выделяются следующие задачи: рассмотреть становление российской банковской системы на современном этапе; исследовать переход к пропорциональному регулированию банковской системы; определить перспективы развития банковской системы России в связи с переходом к пропорциональному регулированию.

Ключевые слова: Центральный Банк, банки с базовый лицензий, банки с универсальной лицензий, банковская система.
1

июня 2017 года в силу вступил Федеральный закон от 1 мая 2017 г. № 92-Ф3 «О внесении изменений в отдельные законодательные акты Российской Федерации» [1]. В соответствии с ним, осуществляющие на территории Российской Федерации деятельность банки могут иметь два вида лицензий - базовую или универсальную, которая зависит от наличия у них собственных средств. Все процедуры, связанные с изменением статуса банковских организаций, были завершены к 1 января 2019 года, и такое изменение в обязательном порядке отражается в их уставе, а также в новой лицензии, в которой отражаются соответствующие новому статусу возможности по проведению банковских операций.

Внесенные в регулирующие банковскую деятельность законодательные изменения выступают достаточно существенными с позиции влияния этого законодательства на структуру и состав в целом отечественной банковской системы, доступность и качество оказываемых ею услуг для юридических и физических лиц. Это также было обусловлено и такими статистическими данными, что на момент принятия указанного нормативного акта только 54,8\% от общего количества банковских организаций (282 банка) обладали собственными средствами, объем которых превышает 1 млрд. руб. Все остальные банки были вынуждены свой бизнес выстра- ивать с учетом новых установленных законодательно требований.

Цель исследования заключается в том, чтобы рассмотреть и проанализировать особенности, которые предоставляет банковским организациям базовая и универсальная лицензии, каким образом они влияют на осуществление их деятельности.

В этой связи были рассмотрены следующие важнейшие вопросы:

1. изучена и дана общая характеристика обоих видов банковских лицензий;

2. приведены различия в возможностях, предоставляемых каждой из них.

Российские банки начали подразделяться на базовые и универсальные в 2018 году и уже через год данная реформа была окончена. Разные авторы и исследователи этого вопроса достаточно по-разному относились к идее вводимого законопроекта, но при этом все сходятся в мысли о том, что в подобной концепции пропорционального регулирования банковского сектора давно назрела потребность, поскольку в российскую практику начинают проникать международные стандарты ведения банковской деятельности. 


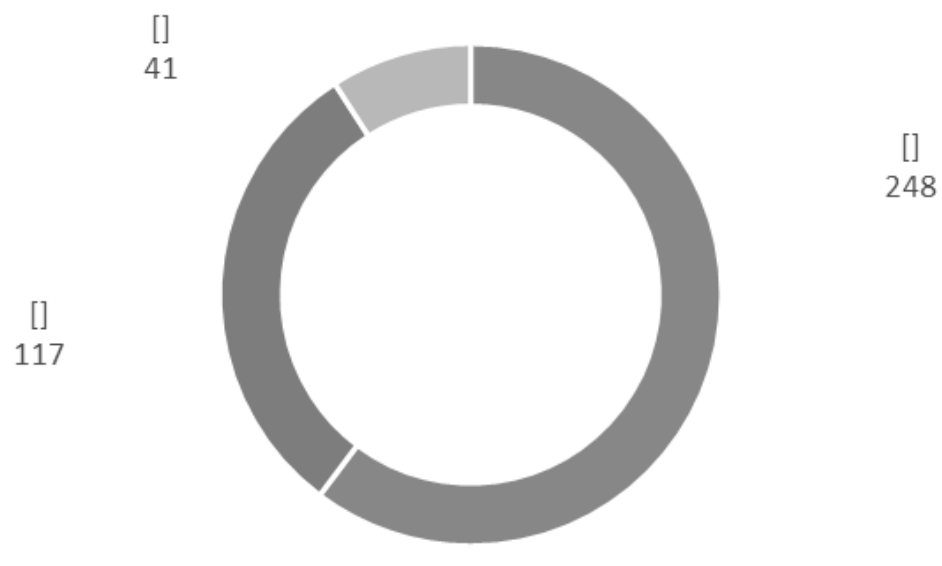

Рис. 1. Структура банковской системы России на 1 февраля 2021 года, ед.

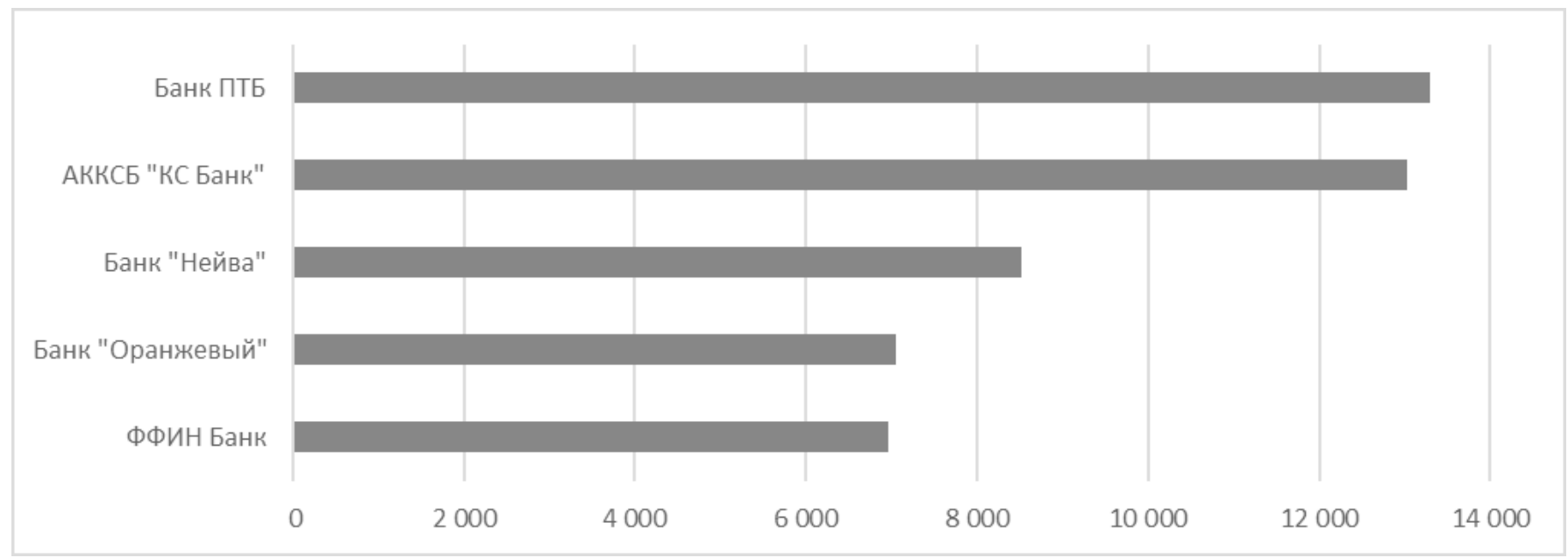

Рис. 2. Самые крупные банки по размеру активов с базовой лицензией на 1 декабря 2020 года, млн. руб.

В качестве основного критерия разграничения банковских организаций с учетом двух видов лицензий выступает их размер капитала. Так, к банкам с универсальной лицензией относятся такие, у которых минимальный размер уставного капитала на момент прохождения процедуры государственной регистрации и получения лицензии составляет 1 млрд. руб., и тем самым обладает правом на реализацию всех видов банковских операций. К банкам с базовой лицензией отнесены такие, у которых размер уставного капитала в объеме 300 млн. руб. и имеет ограничения на проведение банковских операций.

Тем самым получить универсальную лицензию имеют возможность лишь те банковские организации, чей капитал составляет 1 млрд. руб. и более. При этом имеется положение о том, что если банк, обладающий базовой лицензией, имеет собственных средств на сумму трех млрд. руб., то в отношении него будут действовать регуляторные нормы, которые имеют распространение на банки с универсальной лицензией. Это позволяет сделать вывод о том, что базовая лицензия регламентируется в отношении банков, которые имеют небольшие размеры. В соответствии со статистикой, в России на период 1 января 2021 года насчитывалось 117 таких банков, что отражено на рисунке 1. При этом пять самых крупных банков, обладающих базовой лицензией, по размеру собственных активов на эту же отчетную дату, представлены на рисунке 2:

Несмотря на приведенные на рисунке 2 данные, большая часть банковских организаций, которые обладают базовой лицензией, имеют объем собственных средств в среднем 1,8 млрд. руб. В данном сегменте банковской системы суммарные активы на рассматриваемую дату составляют 300 млрд. руб. 
[]

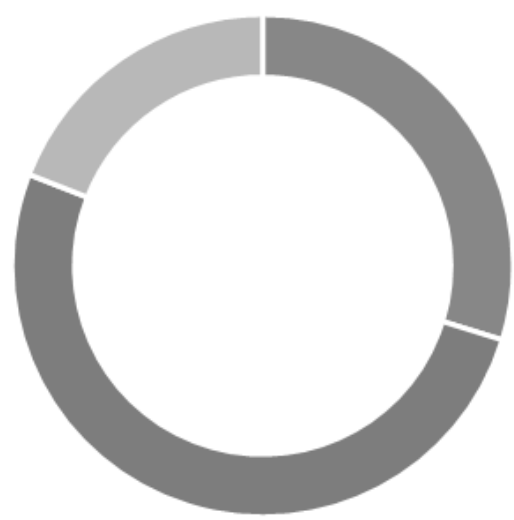

Рис. 3. География расположения банков, имеющих базовую лицензию

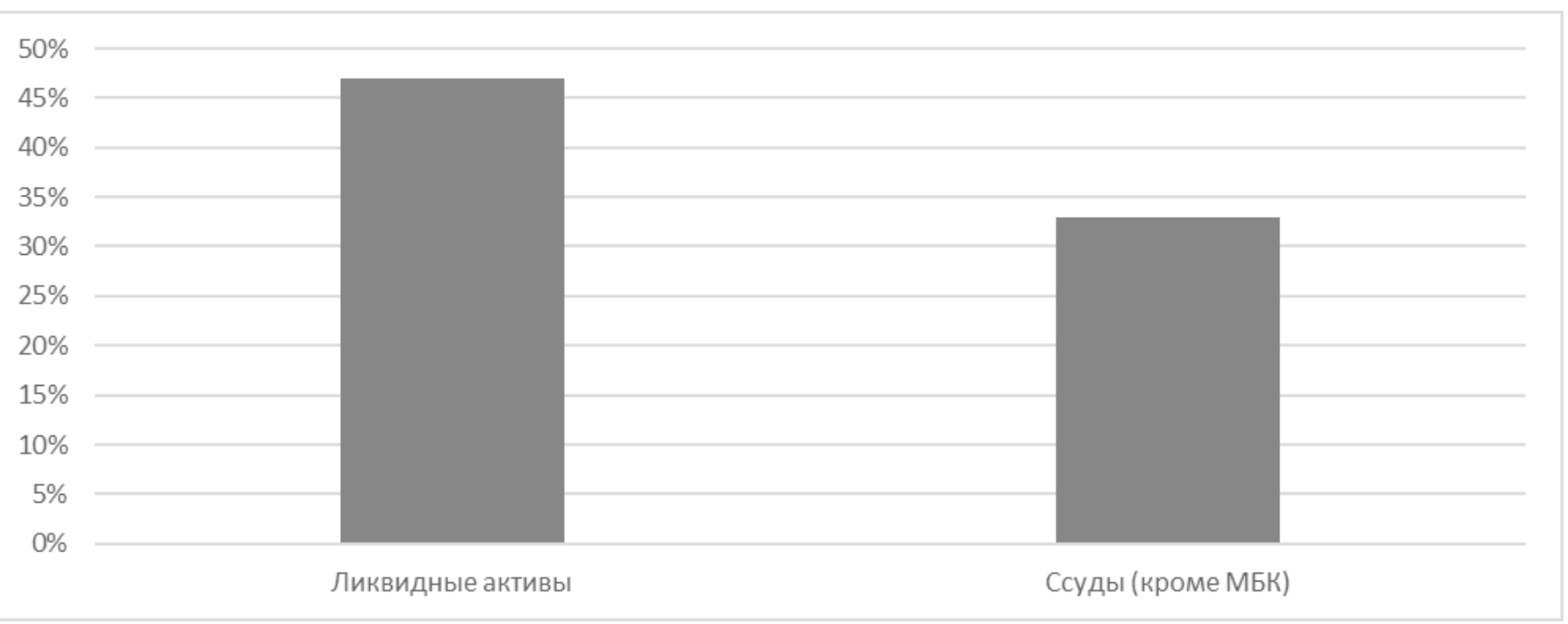

Рис. 4. Вложения банков, имеющих базовую лицензию, на 1 декабря 2020 года,\% от собственных активов

Как правило, в российской практике банки с базовой лицензией являются региональными, в Москве из них зарегистрировано только 28\%. Головные офисы этой категории банковских организаций расположений в 51 российском субъекте, и в четвертой части российских регионов расположено не меньше двух таких банков (рисунок 3).

Приведенные на рисунке 4 статистические данные показывают, что банки, обладающие данным видом лицензии, не имеют высокой активности:

Обладающие универсальной лицензией банки имеют возможность осуществлять все известные виды операций как на территории России, так и за ее границей. Од- нако к таковым банкам отнесена меньшая доля, и в качестве примеров таких финансовых учреждений можно привести «ВТБ», «Сбербанк», «Альфа-Банк», «Открытие», «Газпромбанк».

Тем самым, базовая лицензия дает возможность банку реализовывать все основные операции, такие как открытие счетов и их ведение, осуществление денежных переводов, покупка иностранной валюты и ее продажа. При этом в отношении рассматриваемого вида лицензии существует конкретный перечень ограничений, которые относятся в большинстве случаев к работе финансовых организаций с иностранными клиентами. Нужно отметить, что указанный запрет не имеет своего распространения в том случае, если банк открывает счет 
Таблица 1. Уровень нагрузки в соответствии с банковской лицензией

\begin{tabular}{|c|c|c|}
\hline \multirow{2}{*}{ Базовая лицензия } & \multicolumn{2}{|l|}{ Универсальная лицензия } \\
\hline & Общие требования & Системно значимые \\
\hline $\begin{array}{ll}\text { • } & \text { установленный минимум на объем } \\
\text { · } & \text { собственных средств - } 300 \text { млн. руб.; } \\
\text { требовение бти нормативов; } \\
\text { отчетности, включая и по МСФО, } \\
\text { упрощены; } \\
\text { международные операции } \\
\text { представляются возможными лишь } \\
\text { при участии в них банков, обладающих } \\
\text { универсальной лицензией. }\end{array}$ & $\begin{array}{ll}\text { - } & \text { установленный минимум на объем } \\
\text { собственных средств - } 1 \text { млрд. руб.; } \\
\text { соблюдению подлежать } \\
\text { все имеющиеся нормативы } \\
\text { и международные стандарты; } \\
\text { предоставление полной отчетности, } \\
\text { в том числе и по МСФО; } \\
\text { возможность проведения всех видов } \\
\text { международных операций. }\end{array}$ & $\begin{array}{l}\text { Дополнительно к общим: } \\
\text { н } \quad \text { надбавки и нормативы к капиталу для } \\
\text { СЗКО; } \\
\text { возможность использовать } \\
\text { в управлении банковскими рисками } \\
\text { более продвинутые и передовые } \\
\text { методы. }\end{array}$ \\
\hline
\end{tabular}

Таблица 2. Разрешенные операции банковских организаций в зависимости от вида лицензии

\begin{tabular}{|l|l|}
\hline Универсальная & Базовая \\
Разрешены к осуществлению все виды & $\begin{array}{l}\text { Разрешены все виды операций, за исключением: } \\
\text { банковских операций } \\
\text { размещения во вкладах денежных средств, драгоценных металлов, не могут быть } \\
\text { даны гаранти иностранным лицам; }\end{array}$ \\
$\begin{array}{l}\text { проведения с участием иностранных лиц лизинговых операций и поручительств } \\
\text { по ним; } \\
\text { открытия в иностранных банках корреспондентских счетов, кроме как при } \\
\text { принятии участия в иностранной платежной системе. }\end{array}$
\end{tabular}

за пределами России для принятия участия в иностранной платежной системе.

Если банковская организация не согласна с условиями, которые ей предоставляются по базовой лицензии, то они в обязательном порядке получают один из двух следующих статусов: небанковская кредитная организация либо микрофинансовая компания.

Ранее было определено, что в отношении базовой лицензии современным законодательством и нормативами Н6 устанавливаются более жесткие ограничения, чем это видно в отношении банков, обладающих универсальной лицензией. Это обусловлено и тем фактом, что риск заемщика в их случае будет составлять около $20 \%$ от собственного капитала.

Однако и у базовой лицензии можно обнаружить преимущества. В первую очередь, к ним относится отсутствие необходимости предоставить информацию о принимаемых банковской организацией рисков, об оценке каждого из них. Также можно отметить и отсутствие требования назначить в службе внутреннего контроля руководителя, тем самым его функции можно возложить и на руководителя службы управления рисками. Положительным моментом выступает и то, что число нормативов, которые необходимо соблюдать в обязательном порядке, сокращено. Для базовой лицензии их число составляет 6 против 12 для универсальной лицензии.
В таблице 1 показаны основные существенные различия между исследуемыми видами банковских лицензий:

Основное различие в предоставляемых банковской лицензией возможностях состоит в ограничении осуществления операций, что отражено в таблице 2:

В целом пропорциональное регулирование заключается в следующем (таблица 3):

Таким образом, на основании проведенного исследования можно сделать вывод о том, что в качестве основных характеристик для обоих видов исследуемых банковских лицензий выступает размер собственного капитала каждой банковской организации и совершаемые ею операции. Так, при наличии базовой лицензии банки являются достаточно ограниченными при совершении некоторых видов операций, при этом такие ограничения связаны по большей мере с участием в этих операциях иностранных лиц либо их проведением за пределами России.

При этом каждый вид банковской лицензии оказывает влияние не только на внутригосударственную деятельности финансовых учреждений, но и на российских клиентах. Так, больше внимания клиенты уделяют более крупным банкам, способным предложить им большие варианты проведения операций. Вводимые базовой лицензией ограничения не могут положительно сказы- 
Таблица 3. Особенности пропорционального регулирования

\begin{tabular}{|c|c|}
\hline Универсальная & Базовая \\
\hline $\begin{array}{l}\text { Необходимо обязательное соблюдение в полном объеме } \\
\text { требований международных стандартов }\end{array}$ & $\begin{array}{l}\text { Технически сложные международные стандарты не подлежат } \\
\text { применению }\end{array}$ \\
\hline $\begin{array}{l}\text { Соблюдению подлежат все действующие на сегодняшний день } \\
\text { нормативы }\end{array}$ & $\begin{array}{l}\text { Только шесть нормативов: достаточности основного } \\
\text { и совокупного капитала, текущей ликвидности, концентрации } \\
\text { кредитного риска }\end{array}$ \\
\hline $\begin{array}{l}\text { С начала } 2018 \text { года были введены новые виды нормативов - } \\
\text { финансового рычага и чистого стабильного фондирования }\end{array}$ & Не подлежат применению \\
\hline $\begin{array}{l}\text { Сохранению подлежать нормативы в отношении обязательного } \\
\text { резерва, усреднения обязательных резервов }\end{array}$ & $\begin{array}{l}\text { Эти нормативы не могут быть для этой категории банков выше, } \\
\text { чем это установлено в отношении универсальной лицензии }\end{array}$ \\
\hline $\begin{array}{l}\text { Был внедрен в банковскую практику подход к оценке кредитного } \\
\text { риска своего контрагента с использованием производных } \\
\text { финансовых инструментов }\end{array}$ & $\begin{array}{l}\text { К оценке кредитного риска банковских организаций был } \\
\text { сохранен действующий подход }\end{array}$ \\
\hline $\begin{array}{l}\text { Возможность совершать сделки и операции со всякими ценными } \\
\text { бумагами }\end{array}$ & $\begin{array}{l}\text { Возможно только совершение сделок и операций с ценными } \\
\text { бумагами первого котировального списка Московской биржи }\end{array}$ \\
\hline $\begin{array}{l}\text { В структуре банка запрещено совмещение функциональных } \\
\text { должностей и обязанностей руководителей службы управления } \\
\text { рисками и службы внутреннего контроля }\end{array}$ & В этом случае такое совмещение разрешается \\
\hline Информация подлежит раскрытию в полном объеме & $\begin{array}{l}\text { Требование к раскрытию банками информации упрощено, } \\
\text { например, в отношении управления рисками по МСФО и имеется } \\
\text { упрощенная форма для расчета собственного капитала, } \\
\text { получаемых значениях обязательных нормативов }\end{array}$ \\
\hline $\begin{array}{l}\text { Сохраняется порядок проведения однолетнего цикла оценки } \\
\text { качества за управлением собственным капиталом и его } \\
\text { достаточностью, а также рисками }\end{array}$ & $\begin{array}{l}\text { Используется двухлетний цикл оценки качества, а также } \\
\text { используются показатели для проведение такой внутренней } \\
\text { оценки при соблюдении обязательных нормативов }\end{array}$ \\
\hline $\begin{array}{l}\text { Сохраняется оценка текущего и прогнозируемом экономического } \\
\text { положения банковской организации }\end{array}$ & $\begin{array}{l}\text { Используется сокращенный список показателей при расчете } \\
\text { активов и их ликвидности. При этом Банк России имеет право } \\
\text { на установление особенностей такой экономической оценки }\end{array}$ \\
\hline $\begin{array}{l}\text { Предоставление всех форм отчетности, в соответствии } \\
\text { с Указанием Банка России № 4212-У от } 24 \text { ноября } 2016 \text { года }\end{array}$ & $\begin{array}{l}\text { Не составляются некоторые формы отчетности, например, } \\
\text { «Седения о ценных бумагах, приобретенных кредитной } \\
\text { организацией»; а также составление форм в сокращенном виде, } \\
\text { к примеру, «Сведения об обязательных нормативах, показателе } \\
\text { финансового рычага и нормативе краткосрочной ликвидности» }\end{array}$ \\
\hline
\end{tabular}

ваться на деятельности банка. Именно по этой причине клиенты в него не инвестируют средства в виде вкладов на разные виды счетов, и это может повлиять на будущих клиентов, которые хотели бы начать с конкретной банковской организацией сотрудничество.

При этом создаются условия для возможного перехода банковской организации, владеющей базовой лицензией, в категорию банков, которые имеют универсальную. Это можно осуществить постепенно, с использованием стратегии наращивания капитала и введения в деятельность новых видов операций.

Для решения указанной проблемы некоторые исследователи вопроса указывают на необходимость банков- ским организациям предложить лицензии с разным кругом клиентуры, к примеру, только для среднего и малого бизнеса, только физлица и т.д. С учетом видов лицензии необходимо устанавливать свою систему регулятивных норм, что приведет к образованию специализированных банковских организаций, обладающих уникальным набором банковских технологий и компетенций. Именно такие банки необходимы для промышленно развитых российских регионов, которые способы на рынке банковских услуг занять свою нишу.

Анализ позволяет прийти к выводу о том, что оба вида лицензий отличаются несущественно, и в целом призваны указать на универсальный характер деятельности банковских организаций в обоих случаях. 


\section{ЛИТЕРАТУРА}

1. Федеральный закон от 1 мая 2017 г. № 92-Ф3 «0 внесении изменений в отдельные законодательные акты Российской Федерации» // Российская газета. 2017.— № 94.— 3 мая.

2. Указание Банка России от 24 ноября 2016 г. № 4212-У«0 перечне, формах и порядке составления и представления форм отчетности кредитных организаций в Центральный банк Российской Федерации» // Вестник Банка России. — 2017. — № 12-13.— 27 января.

3. Гаджиева, Д.Г. Актуальные проблемы правового регулирования банковской системы в Российской Федерации / Д.Г. Гаджиева // Молодой ученый.2020.— № 41 (331). — C. 89-91.

4. Гудкова, М.В. К вопросу об универсальных и базовых лицензиях банков Российской Федерации / М.В. Гудкова // Доступность банковских и иных финансовых услуг как правовой принцип эффективного функционирования публичных и частных финансов: Сб. материалов. — Саратов, 2019.—C. $51-55$.

5. Неверова, Н.В. 0 некоторых новеллах правового регулирования функционирования банковской системы Российской Федерации / Н.В. Неверова // Вестник Саратовской государственной юридической академии. — 2018. — № 1 (120). - С. 213-220.

6. Софронов, В.В. Регулирование банковского сектора России. Новые тенденции / В.В. Софронов.— 2018. — Т. 24. — № 2 (770).— С. 335-350.

(с Кырлан Марчел ( marcel_carlan2003@yahoo.com ).

Журнал «Современная наука: актуальные проблемы теории и практики»

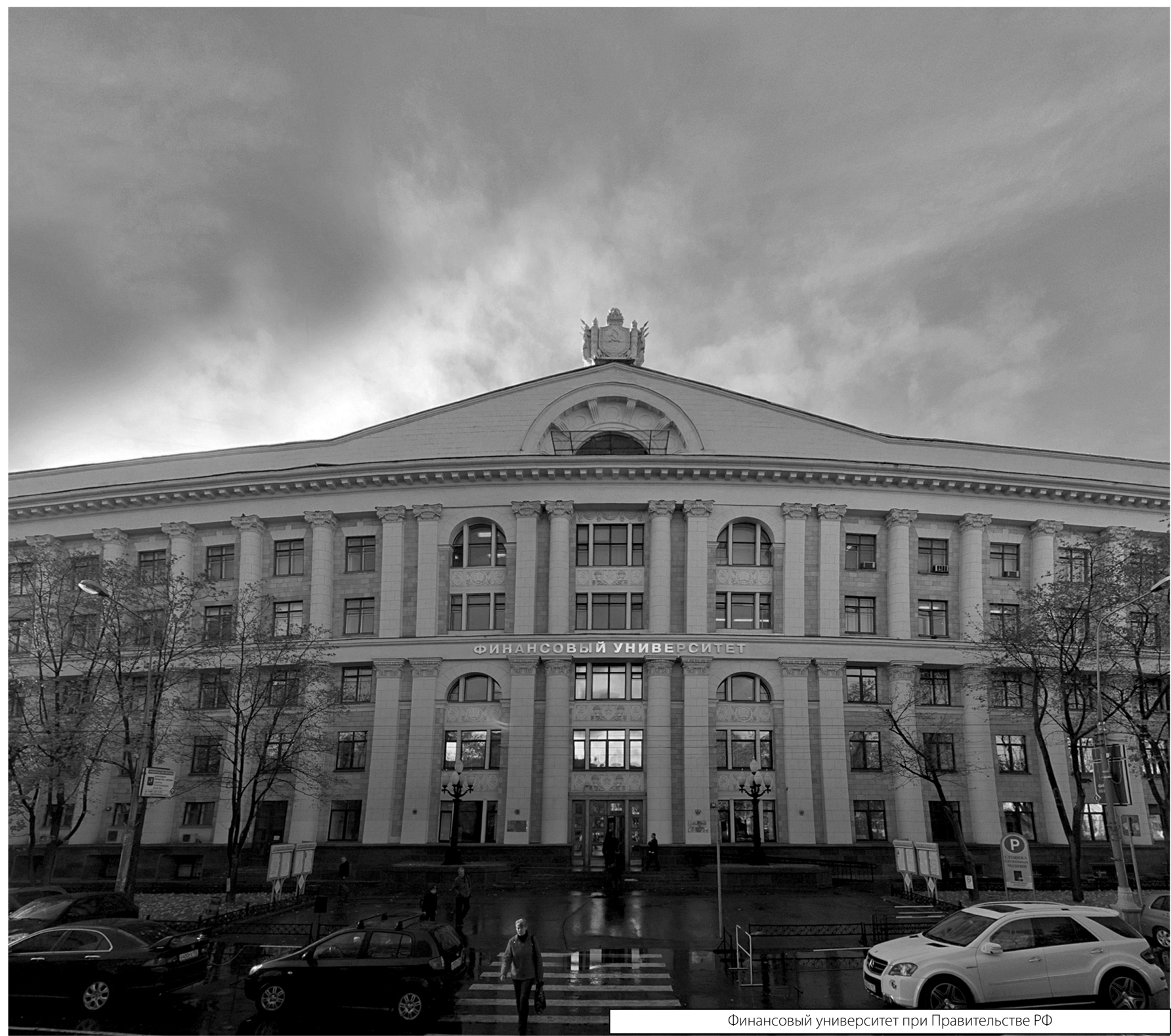

